American J. of Engineering and Applied Sciences 3 (3): 516-520, 2010

ISSN 1941-7020

(C) 2010 Science Publications

\title{
Undergraduate Students' Satisfaction with Hostel and Sense of Attachment to Place: Case Study of University Sains Malaysia
}

\author{
${ }^{1}$ Fatemeh Khozaei, ${ }^{1}$ Ahmad Sanusi Hassan and ${ }^{2}$ Zahra Khozaei \\ ${ }^{1}$ School of Housing Building and Planning, \\ ${ }^{2}$ School of Humanities, \\ University Sains Malaysia, Malaysia
}

\begin{abstract}
Problem statement: Unlike numerous studies have explored residents' satisfaction and sense of attachment to housing, little discussion exists on this area addressing the relationship between sense of attachment to place and student housing satisfaction. To fill such a gap, this article was an attempt to investigate undergraduate students' level of satisfaction and sense of attachment to place drawn from three ethnics (Malay, Chinese and Indian) living in the hostels of University Sains Malaysia to see if there is a significant relationship between the level of satisfaction and sense of attachment to hostel and whether Chinese, Indians and Malay students differ from one another significantly in their satisfaction with hostel and sense of attachment to place. Approach: A 33 item questionnaire measuring satisfaction of students with (hostel fees, sharing the room, hostel distance from facilities provided on University campus and hostel distance from school', hostel design and layout, hostel population, hostel rules and regulations, hostel safety and hostel security and so forth) and sense of attachment to place was used in this research. A sample of 267 (168 Malay, 76 Chinese and 23 Indians) students were randomly selected from seven hostels of University Sains Malaysia. Results: The findings of the study showed a significant positive correlation between level of satisfaction and sense of attachment to place $(r=0.529 ; \mathrm{p}<0.01, \mathrm{n}=267)$. An insignificant difference was found between three ethnics (Malay, Chinese and Indian) on the level of satisfaction with hostel and sense of attachment to place. Conclusion: It was concluded that (1) higher sense of attachment is associated with an increase in level of satisfaction. (2) Satisfaction and attachment to hostel are not affected by the student's ethnicity.
\end{abstract}

Key words: Level of satisfaction, sense of attachment, student housing, ethnicity

\section{INTRODUCTION}

Nowadays, Universities are striving to attract a large number of students to their own programs and adopting different strategies to maintain their own students. Previous research has shown how university accommodation offers influence students' choice Oppewal et al. (2005). Given that universities need to meet a rising demand for students' housing, student's satisfaction with their housing as a determining factor in improving the living environment should be taken into account. However, providing student with such satisfaction is a difficult task due to the public nature of these spaces (Kaya and Erkip, 2001) and even harder, if we realize those individuals' judgments about residential conditions is formed by their needs and desires. Satisfaction with one's residential condition comes from congruency between actual and desired situations. If such an agreement is not met, dissatisfaction could be experienced (Vera-Toscano and Ateca-Amestoy, 2008). Though a lot of factors seem to contribute to student's level of satisfaction, majority of students would prefer to stay in hostels as long as they are provided with decent housing and adequate facilities at a cheaper rate.

Unlike the effort has made to investigate factors influencing residents' satisfaction with their house and neighborhood, The lack of inquiry into students' satisfaction with their university housing seem to suggest more investigation (Amole, 2009). Some research was undertaken on different factors affecting students' satisfaction with living environment.

Investigation of students' perceptions of the residence hall living environment at Kuwait University showed how students' perception could be affected by gender, nationality and duration of residency. Significant differences were found between male and female students' responses on the way they perceived

Corresponding Author: Fatemeh Khozaei, School of Housing Building and Planning, University Sains Malaysia, Malaysia 
their residence hall living environment. Years of residence also could predict students' perception of their living environments. Nonetheless, no significant differences were reported among the responses based on their nationalities.

Barona et al. (1976) explored the impact of social density (an increase in number of roommates sharing a double occupancy) on students' perception of crowding. Their results revealed that "Residents of triples expressed greater feelings of crowding, perceived less control over room activities, expressed more negative interpersonal attitudes and experienced a more negative room ambience". Holahan and Wilcox (1978) demonstrated how floor level could have an effect on students' satisfaction and friendship formation. They came to this conclusion that "residents of low-rise dormitories were significantly more satisfied and established more dormitory-based friendships than residents of a mega-dorm setting".

Physical attributes of hostels have been hardly examined in detail. Kaya and Erkip (2001) study on student housing setting revealed students living on the highest floor perceived their rooms larger and found them less crowded in comparison to those ones on the lowest floor. Further, they concluded that students' perception of their privacy led to an increase in the level of students' satisfaction with dormitory. Fisman (2007) argued "sense of place attempts to capture how and why humans feel connected or "rooted" to a place". In this line, Rodger and Johnson (2005) found that students living in dormitory style buildings have a lower level of sense of belonging to place than those living in suite-style buildings. To fill a gap in literature on the relation between sense of attachment to place and satisfaction with hostel among undergraduate students, this study is an attempt at answering the following questions:

- Is there a significant relationship between sense of attachment to place and satisfaction with university hostels?

- Do Chinese, Indians and Malay students differ significantly in their satisfaction with hostel and sense of attachment to place?

\section{MATERIALS AND METHODS}

A sample of 267 students (205 females and 62 males) was selected randomly from seven hostels of University Sains Malaysia. Data collected in December 2009 and January 2010. The questionnaire comprised 3 main sections:
- Section A: A demographic form was filled out by the participants, including the information on age, gender, race, religion and marital status, year of study, the current hostel and the duration of residency in their current hostel

- Section B: The questionnaire comprised of 28items measuring students' satisfaction with hostel fees paid, sharing with roommates, distance from other facilities and students schools, design and layout of hostels, facility, hostel population, rules and regulations, safety and security was used in this research. The participants rated on 5 point scale their responses from very dissatisfied (1) to very satisfied (5). In this sample, the reliability coefficient is $=0.522$

- $\quad$ Section $C$ : In addition the questionnaire comprised of 6-items measuring students' sense of attachment to Place. The students rated on a 5 point scale their responses from strongly disagree (1) to strongly agree (5)

\section{RESULTS}

The questionnaires were distributed to voluntary respondents and the data was collected individually. A summary and explanation was provided at the beginning of each questionnaire. All respondents were asked to fill out a demographic form and then questionnaire on level of satisfaction with hostels and sense of attachment to place. The respondents were informed about the purpose of the study. After data collection the test sheets were scored. For statistical analysis, Pearson product moment correlation coefficient and ANOVA were applied through Statistical Package for Social Sciences, 16 versions.

Table 1 indicates frequencies and percentages of demographic information i.e. gender, age, religion, ethnicity, marital status, duration of residency, years of study in the university and students' current hostel. The age of the participants ranged from 18-26 years, $99.3 \%$, unmarried and $0.7 \%$ were married. Participants were from 7 hostels of University Sains Malaysia including Bakti Permai 6.8\%, Cahaya Gemilang 14.8\%, Fajar Harapan 4.2\%, Indah Kembara 5.7\%, Restu 28.1\%, Saujana $25.1 \%$ and Tekun $15.3 \%$. The duration of the residency in the current hostel were 0-3 months $23.6 \%$, 3-6 months $15.7 \%$ and 6-12 months $18.7 \%, 1-2$ years $22.5 \%$ and 2 or more years $19.5 \%$.

Table 1 indicates frequencies and percentages of demographic information i.e., gender, age, religion, ethnicity, marital status, duration of stay, years of study in the university and students' hostel. 
Am. J. Engg. \& Applied Sci., 3 (3): 516-520, 2010

Table 1: Frequency table for respondents' demographic information

\begin{tabular}{llc}
\hline Demographic & Variables & Percentage \\
\hline Gender & Female & 76.8 \\
Age & Male & 23.2 \\
& 18-21 years & 61.4 \\
Duration of residency & 22-25 years & 36.7 \\
in the hostel & 2-3 months & 1.9 \\
& 3-6 months & 23.6 \\
& 6-12 months & 15.7 \\
Ethnicity & 1-2 years & 18.7 \\
& 2 years-more & 22.5 \\
Marital status & Chinese & 19.5 \\
& Indians & 28.4 \\
Years in the University & Malay & 8.7 \\
& Married & 62.9 \\
& 1st year & 0.7 \\
& 2nd year & 99.3 \\
Religion & 3rd year & 35.6 \\
& 4th year & 31.5 \\
& Islam & 27.7 \\
& Christian & 5.2 \\
Hostels of University & Buddhist & 65.1 \\
Sains Malaysia & Hindu & 09.0 \\
& Bakti Permai & 19.9 \\
& Cahaya Gemilang & 06.0 \\
& Fajar Harapan & 6.8 \\
& Indah & 14.8 \\
& Kembara & 4.2 \\
& Saujana & 5.7 \\
& Tekun & 28.1 \\
& & 25.1 \\
& & 15.3 \\
\hline
\end{tabular}

Table 2: A correlation (Pearson product moment) between satisfaction with hostels and sense of attachment among Chinese, Indians and Malay students of University Sains Malaysia

\begin{tabular}{ll}
\hline Variable & Satisfaction with hostels \\
$\mathrm{N}$ & 267 \\
Sense of attachment (Pearson r) & $0.529^{* *}$ \\
Alpha & 0.00
\end{tabular}

Note: Verifies positive correlation between satisfaction with hostels and sense of attachment (Chinese, Indian and Malay) significant at $* *: \mathrm{p}=0.01$ (2-tailed)

Table 3: Summary of analysis of variance for the satisfaction with hostels among Chinese, Indians, Malay ( $\mathrm{N}=267)$

\begin{tabular}{llrllll}
\hline Variable & Ethnicity & \multicolumn{1}{c}{ Mean } & SD & DF & Sig & F \\
\hline Satisfaction & Chinese & 100.57 & 15.221 & 2.264 & 0.894 & 0.112 \\
with hostel & Indians & 100.04 & 12.009 & & & \\
& Malay & 99.66 & 13.233 & & & \\
\hline
\end{tabular}

An insignificant difference was found between Chinese, Indian and Malay ( $\mathrm{f}=0.112, \mathrm{DF}=2,264, \mathrm{p}>0.05)$ on satisfaction with hostels of University Sains Malaysia

To examine the relationship between scores of satisfaction with hostel and sense of attachment a bivariate correlation was performed. Table 2 shows that positive correlation was established between satisfaction with hostel and sense of attachment $(\mathrm{r}=0.529 ; \mathrm{p}<0.000, \mathrm{~N}=267)$.
Table 4: Post Hoc LSD analysis among Chinese, Indians, Malay on the variable of satisfaction with hostels $(\mathrm{N}=267)$

\begin{tabular}{lllcll}
\hline Variable & Ethnicity & Ethnicity & MD & SE & Sig. \\
\hline Satisfaction & Chinese & Indians & 0.524 & 3.275 & 0.873 \\
with hostel & & Malay & 0.903 & 1.910 & 0.637 \\
& Indians & Malay & 0.379 & 3.048 & 0.901 \\
& Malay & Indians & -0.379 & 3.048 & 0.901
\end{tabular}

Note: An insignificant difference $(p>0.05)$ was found between (Chinese, Indians and Malay) on the satisfaction with hostels of University Sains Malaysia

Table 5: Summary of analysis of variance for the variable of sense of attachment among Chinese, Indians, Malay ( $\mathrm{N}=267)$

\begin{tabular}{lllllll}
\hline Variable & Ethnicity & Mean & SD & DF & Sig & F \\
\hline Sense of & Chinese & 22.58 & 4.722 & 2.264 & 0.719 & 0.330 \\
attachment & Indians & 21.87 & 4.939 & & & \\
& Malay & 22.02 & 5.511 & & & \\
\hline
\end{tabular}

Note: An insignificant difference was found between Chinese, Indians and Malay $(f=0.330, D F=2,264, p>0.05)$ on sense of attachment $\mathrm{p}>0.05$

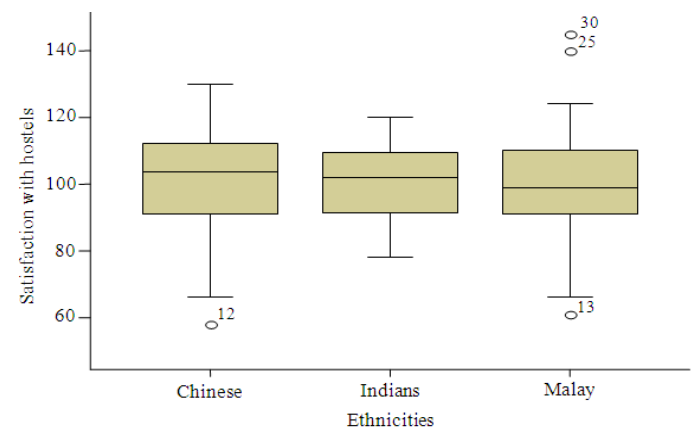

Fig. 1: Mean scores on the variable of satisfaction with hostels among Chinese, Indians and Malay students

Table 3 and Fig. 1 show mean scores on satisfaction with hostel among Chinese, Indians and Malay students. This illustrates insignificant difference ( $f=0.112$, df $=2,264, p>0.05$ ) on satisfaction with hostels of University Sains Malaysia. Furthermore, LSD Table 4 shows that on the variable of satisfaction with hostel there is insignificant difference between (Chinese, Malay and Indians) students. Satisfaction with hostel was determined by different aspects of hostel for example, hostel in general that include space of room, facilities available in hostel, maintenance and cleanliness, security, food quality and so forth. Table 5 and Fig. 2 show mean scores on the sense of attachment to place among Chinese, Indians and Malay students. According to the results, insignificant difference was found ( $\mathrm{f}=0.330, \mathrm{df}=2,264, \mathrm{p}>0.05$ ) on the variable of sense of attachment. In addition, LSD Table 6 illustrates insignificant difference between (Chinese, Indians and Malay) on the Sense of Attachment to place. 


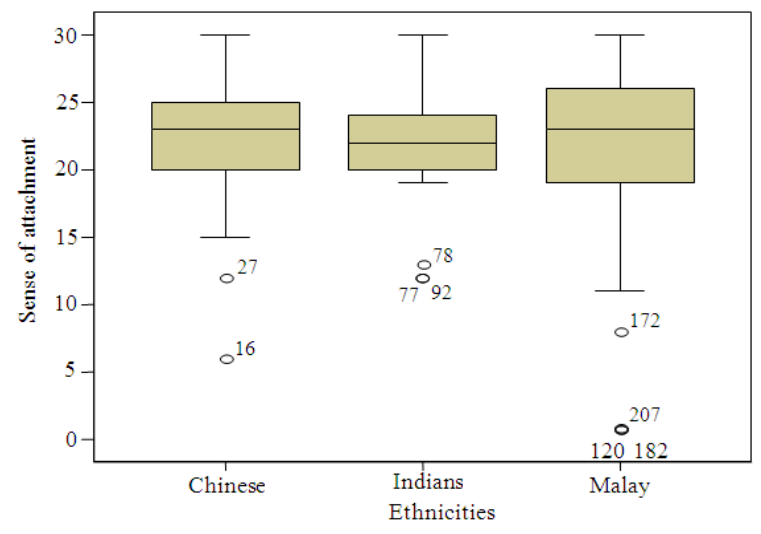

Fig. 2: Mean scores on the variable of sense of attachment among Chinese, Indians and Malay students

Table 6: Post Hoc LSD analysis among Chinese, Indians, Malay on the variable of sense of attachment $(\mathrm{N}=267)$

\begin{tabular}{lllrll}
\hline Variable & Ethnicity & Ethnicity & \multicolumn{1}{l}{ MD } & SE & Sig. \\
\hline Sense of & Chinese & Indians & 0.712 & 1.255 & 0.571 \\
attachment & & Malay & 0.558 & 0.732 & 0.447 \\
& Indians & Malay & -0.154 & 1.168 & 0.895 \\
& Malay & Indians & 0.154 & 1.168 & 0.895 \\
\hline
\end{tabular}

Note: An insignificant difference $(\mathrm{p}>0.05)$ was found between (Chinese, Indians and Malay) on the sense of attachment $\mathrm{p}>0.05$

\section{DISCUSSION}

The aim of the study was to investigate level of satisfaction and sense of attachment to place among three ethnics (Chinese, Malay and Indians) with the case study of University Sains Malaysia. Moreover, it was assumed that there would be a positive relationship between sense of attachment and satisfaction with hostel.

A bivariate correlation was performed to assess the relationship between scores of satisfaction with hostel and sense of attachment. Result shows that positive correlation was established between satisfaction with hostel and sense of attachment $(r=0.529 ; \mathrm{p}<0.000$, $\mathrm{N}=267$ ). This result illustrate that satisfaction with hostel could predict sense of attachment which is consistent with formulated hypothesis. As like other factors, sense of attachment is positively associated with hostel satisfaction. The possible explanation of this finding is that duration of stay in hostel, satisfaction with space, facilities and so on not only gives satisfaction but also contributes in developing sense of attachment to place. As sense of attachment is an emotional bond towards the place that can be strongly linked with age, length and need for affiliation.

The result of study also reveals that on the variable of satisfaction with hostel there is insignificant difference between (Chinese, Malay and Indians) students. The result shows that generally students were satisfied with hostels of University Sains Malaysia. Satisfaction with hostel was determined by different aspects of hostel for example, hostel in general that include space of room, facilities available in hostel, maintenance and cleanliness, security, food quality, distance from main facilities in campus and so forth in this study.

Additionally according to the results of this study, there is an insignificant difference between (Chinese, Indians and Malay) on the Sense of Attachment to place. This suggests that attachment with the hostel is an emotional bond between students and the hostel and it is not affected by the culture or any ethnicity. This reflects from the results also that student from different ethnicities (Chinese, Malay and Indians) all are approximately equally attached with the hostels.

To conclude, overall findings of the study suggest:

- Generally the students had a positive and satisfactory responses towards hostel of University Sains Malaysia

- A significant correlation found between level of satisfaction and sense of attachment

- An insignificant difference was found between three ethnics (Malay, Indian and Chinese) students of satisfaction with hostel and sense of attachment to place

There are some limitations of the present study. First, the afore-mentioned findings are derived from a purposive convenience sampling process; therefore, the generalizability of the findings is limited. Second, in this study few hostels of University Sains Malaysia were used for data collection. Comparison and study of larger number of respondents in different university settings can be beneficial for understanding the student's level of satisfaction towards hostel.

\section{CONCLUSION}

The result of this study reveals that (1) high sense of attachment is associated with an increase in level of satisfaction. (2) Satisfaction and attachment to hostel is not affected by students' ethnicity.

\section{REFERENCES}

Amole, D., 2009. Residential satisfaction in students' housing. J. Environ. Psychol., 29: 76-85. DOI: 10.1016/j.jenvp.2008.05.006 
Baron, R.M., D.R. Mandel, C.A. Adams and L.M. Griffen, 1976. Effects of social density in university residential environments. J. Personal. Soc. Psychol. 34: 434-446. DOI: 10.1037/0022-3514.34.3.434

Fisman, L., 2007. Sowing a sense of place: An in-depth case study of changing youths' sense of place. Ph.D. Thesis, Department of Urban Studies and Planning. Massachusetts Institute of Technology, Massachusetts, pp: 28.

Holahan, C.J. and B.L. Wilcox, 1978. Residential satisfaction and friendship formation in high and low rise student housing: An interactional analysis. J. Educ., Psychol., 70: 237-241. DOI: 10.1037/0022-0663.70.2.237

Kaya, N. and F. Erkip, 2001. Satisfaction in a dormitory building: The effects of floor on the perception of room size and crowding. Envieron. Behav., 33: 35-53. DOI: 10.1177/00139160121972855
Oppewal, H., Y. Poria, N. Ravenscroft and G. Speller, 2005. Student Preferences for University Accommodation: An Application of the Stated Preference Approach. In: Housing, Space and Quality of Life, Mira, R.G., D.. Uzzell, J.E. Real and J. Romay (Eds.). Ashgate Publishing, ISBN: 10: 075462550, pp: 175.

Rodger, S.C. and A.M. Johnson, 2005. The Impact of residence design on freshman outcomes: Dormitories versus suite-style residences. Can. J. Higher Educ., 35: 83-99.

Vera-Toscano, E. and V. Ateca-Amestoy, 2008. The relevance of social interactions on housing satisfaction. Soc. Indicat. Res. 86: 257-274. DOI: 10.1007/s11205-007-9107-5 